\title{
LA EXPANSIÓN URBANA IBÉRICA POR AMÉRICA Y ASIA. UNA CONSECUENCIA DE LOS TRATADOS DE TORDESILLAS
}

POR

\author{
FRANCISCO DE SOLANO
}

Centro de Estudios Históricos. CSIC Madrid

Se analizan las expansiones española y portuguesa, partiendo del meridiano establecido en Tordesillas. La ocupación espacial hispanoamericana alcanza, desde bien temprano el siglo XVI, unos limites, geográficos desproporcionados: no obstante se procede a su colonización e integración. Los medios para obtenerlos (Asia y África incluidas, también) se verifica sobre el núcleo urbano -ciudad, villa, pueblos de indios, aldeias-, cuyo proceso se acomete en diversas fases: destacando el elevado número de fundaciones en el mundo hispánico y señalando el escaso (aunque significativo) número de fundaciones lusoamericanas.

La mayor parte de las consideraciones que se hacen sobre el Tratado de Tordesillas se hacen a posteriori: conociendo los ámbitos geográficos por donde se verificó la expansión hispanoportuguesa. Así, se analizan con extremado cuidado las políticas geoestratégicas, las ambiciones espaciales, los entramados jurídicos, los incentivos comerciales, lo mismo que las dificultades técnicas con las que se enfrentaron las administraciones de Castilla y de Portugal. No son frecuentes, sin embargo, los estudios que consideren -gradualmente- la proyección y materialización del Tratado sobre la propia expansión ibérica fuera de 
Europa. Tordesillas fue el segundo intento diplomático -después de Alcáçovas- en dar solución a los problemas que podrian nacerse después de una expansión territorial por unos espacios geográficos aún por explorar, por ocupar y por incorporarse a los dominios de Portugal y de Castilla. Fue, pues, una tentativa precautoria, que dice mucho de los alcances políticos de Juan II y los Reyes Católicos, que prefirieron mejor esta fórmula que resolver sus diferencias agresivamente en una ruptura de relaciones y la guerra subsiguiente. Como no se conocían cuáles, en realidad, eran los ámbitos geográficos, ni qué tierras contenían, una solución armada con objetivos inconcretos resultaba la peor y menos práctica de las fórmulas.

Tordesillas resulta, pues, la segunda concordia de la historia ultramarina luso-española, a pesar de las posturas radicales y de la inflexibilidad de los diplomáticos reunidos en la villa, empeñados cada parte en la defensa de sus argumentos. Portugal y España comienzan su protagonismo expansivo, cada una por rumbos diferentes, bajo la serenidad de un compromiso diplomático.

Esta expansión española por gran parte de América y Asia fue realizada formulando, trazando y desarrollando numerosas fronteras y -ya consolidado el espacio- haciéndolas retroceder a otros límites, animadores de otras expansiones. Esta frontera ultramarina puede encararse como un proceso de larga duración, abarcando el tiempo y ámbitos que empleó la expansión española para asentarse, de modo permanente, por gran parte de América. Son las zonas que fueron fronteras con tierras de aborígenes o de otras potencias europeas, tarea ésta que se crece desde el siglo XVII. Unas fronteras más o menos indeterminadas, pero originales y nuevas para el español, a pesar de provenir de un país conformado por muchos trazos fronterizos. En efecto, la Península Ibérica ha contenido desde bastantes siglos muchas fronteras: las medievales se forman desde el año 750 a los finales del siglo $\mathrm{xv}$, donde musulmanes y cristianos mantuvieron fronteras de intenso intercambio hasta, precisamente, el 2 de enero de 1492 en que se ocupa Granada, capital del último reino musulmán.

Estas situaciones divisorias de civilizaciones y mentalidades, pero potenciadoras de las más variadas formas de intercambio, se llevaron a cabo en América desde su descubrimiento, desde

R. I., 1996, n." 208 
1492. América comenzó siendo, toda ella, una frontera y en su colonización por los españoles y otros europeos conquistadores, se repitieron los procesos ocupacionales con los ingredientes humanos y sociales de la frontera: ansia de promoción social, cambio, afán de poder, tierras y bienestar, individualismo; también actitudes aventureras, heróicas y desalmadas.

La institución más poderosa para la pacificación, ocupación y españolización de gran parte de América fue la ciudad. Las fundaciones urbanas (ciudad, villa, pueblo de indios) aquietaron el territorio consiguiendo hacer retroceder la frontera hacia otras zonas, donde se procedía con idéntica metodología. Frontera cambiante que fue desapareciendo cada vez que se integraba y consolidaba un área: haciendo retroceder hacia los interiores las zonas fronterizas, e iniciando en estos nuevos espacios los mismos elementos que habían contribuido a integrar los anteriores: el núcleo urbano en primer lugar, y desde éste desarrollando las promociones y desarrollos agrícolas y ga-' naderos, técnicos y culturales.

Hubo otras tres instituciones que colaboraron en la conformación e integración de la Frontera: la misión -también llamado pueblo de indios- evangelizado por el clero, y el presidio: el fuerte, vigilante defensor. Cada una de estas dos instituciones tiene objetivos y desarrollos diferentes. El pueblo de indios resulta el intento español de reunir a la población indígena -generalmente dispersa- en unidades poblacionales más o menos grandes, dirigidas por autoridades aborígenes y con la atención espiritual cristiana del religioso. El fuerte, por su lado, también denominado presidio, ocupado por colonos-militares con sus familias, junto a indios aculturados, protegían en algunas fronteras la seguridad de pueblos de indios del ataque de otros aborígenes aún no urbanizados. La tercera institución es el real de minas, el poblado levantado junto al yacimiento de mineral ya suficientemente desarrollado, pero aún dirigido por funcionarios de hacienda, antes de alcanzar los niveles municipales. La denominación de «real» supone que aún no había alcanzado la aldea el rango municipal (villa, ciudad). El municipio, pues, categoriza al núcleo urbano.

El análisis de este proceso fundacional urbano español, fenómeno de larga duración, debe encarar -para su explicación y comprensión- el desarrollo de cada uno de estos elementos, 
llamados a tener un relevante protagonismo: ciudad o villa, pueblo de indios/misión, real de minas, fuerte/presidio. En 1492 Cristóbal Colón fundó el Fuerte de Navidad, en la isla Española, el primer asentamiento europeo en el Nuevo Mundo, y así llamado por haber sido levantado el 25 de diciembre de ese año.

A partir de las conclusiones de la Concordia de Tordesillas se marcaron las actuaciones de los hispano-lusitanos. Los espacios delimitados tan difícilmente -a partir de un meridiano a 370 leguas al oeste de las islas de Cabo Verde- quedarían integrados dentro de las soberanías respectivas sostenidos por el símbolo enraizador de la ciudad.

La construcción del mundo iberoamericano sigue ritmos y etapas fundacionales diferentes. Portugal aplicó en su Brasil las pautas que ya había iniciado desde mediados del siglo xv en África, mientras España tiene sus propias pautas que le permiten, con una sorprendente actividad, ocupar medio continente americano en apenas una centuria. Aquí se pretende particularizar este proceso español, señalando -aunque apenas fugazmente- el proceso urbano portugués para detallar el desarrollo de cada uno de estos grandes pueblos civilizadores, desde Tordesillas (1494) hasta cuando fue más necesario poner en práctica las verdaderas líneas de demarcación; es decir, desde 1680, con las reclamaciones españolas por la fundación ilegal portuguesa de Colonia del Sacramento en la orilla izquierda del estuario del Río de la Plata: ilegal por contravenir, precisamente, los enunciados de Tordesillas.

\section{1. ÁṀBitos DE LA EXPANSIÓN IBÉRICA DURANTE EL SIGLO XV}

Los pueblos de la Península Ibérica son los primeros europeos que logran salir de su continente y asentarse en tierras ignoradas de otros continentes. Gracias a unas específicas características humanas, socioeconómicas y técnicas los portugueses y españoles protagonizan la hazaña invulgar -por no existir precedente- de fundar unidades poblacionales en nuevos espacios, muy alejados de sus bases europeas. En estas nuevas fundaciones se desarrollan variadas actividades, en estrecho contacto 
con la población aborigen y estableciendo una constante relación.con la metrópoli. La expansión portuguesa se adelanta en medio siglo a la castellana. Desde la toma de Ceuta (1415) Portugal emprende una fuerte política expansiva, a base de factorías, en el norte de África, verificando en Berbería casi los mismos objetivos espirituales y económicos que habían desarrollado los reinos cristianos con los musulmanes en la Península durante centurias. Estas actividades se encaran recurriendo a las factorías: ensayando su presencia en el noroeste de África ocupando (o fundando) una ciudad costera, aislada y muy bien defendida: desde la que se establecen las mayores relaciones comerciales posibles con el interior: factorías que resultan modelos muy usados y repetidos durante la Baja Edad Media. Castilla, por su lado, intentaba en Granada alcanzar la reconquista total del territorio español, por la que se guerreaba, obstinadamente desde hacía siete centurias.

La proyección ultramarina portuguesa iniciada con la ocupación de Ceuta sigue alcanzando hitos en su carrera descubridora (Cabo Bojador, 1435; Cabo Blanco, 1441) hasta alcanzar la costa de África trasahariana (Argüim y Senegal, 1444), donde se levantan sendas factorías, lo mismo que en el África Central (Sao Jorge da Mina, 1470; Benim, 1486, Luanda, 1490). Pero entre ambos grupos de factorías -las berberiscas y las ultrasaharianas- Portugal descubre tres archipiélagos despoblados, a bastante distancia de la costa dos de ellos (Madeira, 1425; Azores, 1440) y a escasa el tercero (Cabo Verde, 1428): procediéndose a su poblamiento y colonización. Surgen así las poblaciones de Funchal (1440), Sao Vicente (1449), Gaula (1452), Vila do Porto de Sao Miguel (1460), Faial (1480). Todos estos núcleos urbanos repiten el modelo urbanístico medieval de trazado irregular y discontinuo, tal como los portugueses metropolitanos.

Al mismo tiempo que se verifican estos primeros esfuerzos expansionistas se han ido intensificando las rivalidades castellano-portuguesas por la soberanía de las dos grandes islas del archipiélago de Canarias; diferencias que se enrarecen durante la guerra peninsular por la sucesión al trono de Castilla. La paz de Alcáçovas (1479) solucionaba las tensiones peninsulares, pero sobre todo regulaba las áreas de influencia de las dos potencias ibéricas: estableciéndose el sur del paralelo de 
Canarias como área reservada a las actividades expansionistas portuguesas.

De Alcáçovas a Tordesillas presuponen unos escasos, pero muy activos años que se traducen para Castilla en su guerra de reconquista del Reino de Granada y en la ocupación de Tenerife y Gran Canaria. En ambos territorios se procede a la fundación de nuevos núcleos urbanos: Puerto Real (1488) y Santa Fe (1491) en Andalucía -en Cádiz y Granada, respectivamente- y Las Palmas de Gran Canaria (1493). En los tres casos se emplea un modelo de trazado regular, que va a tener una influencia portentosa en el Ultramar español. Este modelo en damero no era muy frecuente en Europa, aunque existían ejemplos en algunas villas no amuralladas del camino de Santiago y en otras nuevas poblaciones españolas (Briviesca, Castellón, etc.), así como en las bastidas francesas. Portugal, por su lado, en estos años entre las Paces de Alcáçovas (1480) y de Tordesillas (1494) verifica un incremento expansivo hacia el Oriente, gracias, entre otras cosas, a la notable actividad económica operada en sus archipiélagos atlánticos, cuya más relevante gesta se realiza en 1498 cuando Vasco de Gama logra, doblando el Cabo de Buena Esperanza, separarse del Atlántico para alcanzar por vez primera, viniendo desde Europa, el océano Índico.

La hazaña de Colón representaba, en este panorama, una posibilidad diferente, no contemplada, aparentemente situada en el victorioso (y monopolizado) camino portugués hacia la sempiterna India: unas nuevas tierras -y confianza de otras por descubrir- cuya soberanía debían, obligadamente, que ser resueltas por medio de los convenios diplomáticos. Eso es Tordesillas.

En Tordesillas se razonan unos ámbitos de influencia. Pero la ocupación de estos espacios quedó a la iniciativa, esfuerzos y ansias expansionistas de cada una de las dos potencias ibéricas. Problemas de interpretación técnica del propio tratado, como cuáles eran y por dónde se delineaban las exactas medidas de demarcación establecidas para aquellas áreas de influencia, motivaron otras reuniones diplomáticas bilaterales. Pero mientras no se llegó a una solución definitiva -es decir, 1778- España y Portugal continuaron, con mayor o menor fortuna, su expansión por los ámbitos geográficos que les correspondían, a ambos lados de unas líneas imaginarias e imaginadas.

R. I., 1996, n." 208 


\section{PROCESO FUNDACIONAL EN EL ULTRAMAR IBÉRICO}

La formación urbana del ultramar ibérico se desarrolla con la construcción de un elevadísimo número de núcleos urbanos dispersos por un paisaje tricontinental: en África, en Asia, en América. A pesar de esta espectacularidad no existen análisis de historia comparada que sigan la formación, construcción y desarrollo de tan formidable empresa. Sólo existen unos contados estudios que resaltan la urbanización hispanoamericana a nivel continental, pero este ejemplo no se sigue en las otras áreas y continentes: que, con perfecto derecho calificativo, puede hablarse de una Iberoáfrica y de una Iberoasia.

Los desarrollos urbảnos ultramarinos ibéricos se verifican, -el portugués y el español- a lo largo de varias fases. Aquí se tratará, apenas, de la urbanización española aunque con referencias puntuales al desarrollo portugués. Representando este primer empeño de historia comparada una llamada invitativa para que sea contemplado en conjunto el fenómeno de la expansión ibérica por Ultramar: que, atado a las fundaciones urbanas, es el mejor resultado de las conclusiones de Tordesillas.

La formación urbana del mundo hispanoamericano se İleva a cabo a lo largo de varios períodos, definidas por factores de geopolítica urbana española, que resuelven el asentamiento español y su comportamiento. En 1520, 15.73 y 1745 se marcan situaciones que califican poderosamente la expansión española -lo que significa fundación de núcleos urbanos- por diferentes espacios americanos: todas ellas muy al oeste de la Línea de Tordesillas. Unas veces aquellas situaciones provienen de los niveles culturales del mundo aborigen conquistado (antes y después de 1520), otras veces procede de la política española (1573) y otras, en fin, motivadas por las medidas de la Ilustración con el fin de promover los espacios semidespoblados o marginales.

Todos estos resultados urbanizadores se analizan encuadrados por las reuniones diplomáticas bilaterales habidas entre las dos potencias ibéricas desde Tordesillas. Junto a ellos, igualmente, se apuntan -no más- los alcances urbanizadores portugueses, sobre todo en América. Unos y otros desarrollos urbanos supusieron sólidos argumentos en las sesiones diplomáticas. 


\section{DE 1494 a 1529}

Es decir, desde el Tratado de Tordesillas al Convenio de Zaragoza. Diplomáticos y técnicos portugueses y españoles realizaron varias reuniones oficiales a partir de lo estipulado en Tordesillas, a fin de llevar a cabo las conclusiones formuladas en la villa vallisoletana. En 1505 en Toro se celebra una junta, por la que España reafirma apoyos jurídico-diplomáticos, una vez verificado por los descubrimientos geográficos realizados que confirman la existencia de un mundo nuevo. En estos nuevos espacios el español reafirma su soberanía fundando núcleos urbanos ex nihilo: al no poder aprovechar los esquemas urbanos de las Antillas por inexistentes. Igualmente en Canarias. El fenómeno fundacional se verifica, en paralelo, tanto en el archipiélago canario, como en el antillano, desde donde se salta (o asalta) a tierra firme: Isabela (1493), Concepción de la Vega (1493), Santo Domingo (1498), Tenerife (1498), Puerto Plata (1504), traslado ciudad de Santo Domingo (1504).

Los intentos por aplicar correctamente el Tratado de Tordesillas lleva, desde Toro, a otra junta, reunida en Burgos (1508) para interpretarlo certeramente, con el fin de aplicarlo a las rutas marítimas que debían seguir las expediciones españolas; sobre todo, la que seguía transversalmente el Atlántico -de Cádiz a Antillas- en una larga y difícil navegación. Intenciones que se radicalizan en 1524, cuando los españoles alcanzan Molucas: en las juntas celebradas en Badajoz y Elvas, a uno y otro lado de los ríos fronterizos de Guadiana y Caia.

En el primer cuarto del siglo xvi la expansión ibérica resulta, en verdad, extraordinariamente dinámica; señalada como una de las más formidables actividades ocupacionales llevadas a cabo por los europeos, y que se continuaría, con idéntico signo, hasta el final del xvI.

Los españoles ocupaban primero La Española, Cuba y Puerto Rico, para desde estas grandes islas saltar al continente e iniciar la penetración de grandes espacios, ocupados por una serie de pueblos aborígenes, de diferente cultura, pero con importante cultura urbana bastantes de ellos. La red urbana hispanoamericana es significativa, y apenas se resalta aquí la cronología de las fundaciones, para destacar la prontitud y diligencia de los españoles por ocupar unos espacios geográficos, 
definidos diplomáticamente en Tordesillas. En Antillas: Nueva Sevilla de Jamaica (1509), San Juan de Puerto Rico (1510), San Cristóbal de La Habana (1510); luego, en Tierra Firme, Santa María la Antigua (1510), Nombre de Dios (1510), Acla (1514), Natá (1517), Panamá (1519), Veracruz (1519) y Nueva Cádiz en la isla venezolana de Cubagua (1510) y Cumaná (1522).

La cronología y geografía de las fundaciones responden a las directrices seguidas por las huestes de la conquista, desde sus bases operacionales de México, Panamá, así como a todo lo largo de los Andes, desde Bogotá a Chile. A la cabeza de puente de Veracruz (1519) se suceden los asentamientos de MéxicoTenochtitlan (1521), Tlaxcala (1521), Valladolid de Michoacán (1526) y Antequera de Oaxaca (1528), a los que siguen Pátzcuaro (1529) y Cholula (1529). Por su lado, la ocupación de América Central se procede tanto desde las bases de Panamá, como desde las de México. Del primer movimiento poblador se fundan en Nicaragua y Honduras las ciudades de Bruselas (1524), Gracias a Dios (1524), León (1524) y Trujillo (1525) en zonas de señalada demografía aborigen, que garantizaba asientos prometedores. Desde Nueva España se continúa el ímpetu fundacional con Guatemala (1524), Quetzaltenango y San Salvador (1524).

El expansionismo portugués alcanza las costas brasileñas -la tierra de la Santa Cruz- en 1500, pero no será sino hasta 1533 cuando se realicen intentos de colonización, y siempre litoralizada. Durante este primer cuarto del siglo XVI los portugueses continúan su ritmo imparable hacia el oriente: radicándose en algunos enclaves costeros de la costa oriental africana (Sofala, Mozambique, Zanzíbar), mientras en las costas asiáticas del Índico logran imponer las bases de una red de fortalezas en la India (Goa, 1510), Malaca (1511) el puerto más pujante de Asia, Ceilán (Colombo, 1518) y Molucas. Pero en 1521 Fernando de Magallanes llega a Filipinas siguiendo una derrota inimaginable.

El viaje circumnavegador de Magallanes y su llegada a Molucas motivó muy serios problemas sobre soberania, que justificaron reuniones bilaterales hispanoportuguesas interpretativas del antimeridiano de Tordesillas, como anteriormente se habían procedido por cuestiones técnicas en Elvas y Badajoz (1524). En los Acuerdos de Zaragoza (1529) Carlos I cedía al rey de Portugal sus posibles derechos sobre Molucas -con 
derecho a retrovendo- a cambio de 300.000 ducados de oro. Las rivalidades ibéricas se solucionaban, por tercera vez, por medios pacíficos.

\section{De 1530 a 1681}

El siguiente bloque temporal entre dos tratados, con referencia a problemas limítrofes, abarca siglo y medio: que es la distancia entre el Tratado de Zaragoza (1529) y los suscritos nuevamente en las ciudades fronterizas de Badajoz-Elvas (1681). En esos ciento cincuenta años se verifica y se robustece la expansión ibérica, de forma espectacular, en los ámbitos geográficos reservados a cada potencia; aunque, igualmente, se verifican retrocesos. Este amplio período puede acotarse, para su mejor comprensión, por un hecho histórico de fundamental importancia: la incorporación de Portugal y su imperio a la Corona de los Reyes de España (1580-1640). Este hecho hace que, teóricamente, deja de categorizarse durante sesenta años la línea de demarcación -como división política- para representar, apenas, un límite divisorio de jurisdicciones de un mismo imperio. No obstante durante, precisamente, esos sesenta años se verifica la penetración y ocupación ilegal portuguesa en zona española de Paraguay. Un hecho consumado que se perpertuaría en razón de su utis possidetis.

\subsection{De 1530 a 1580}

La ocupación española tiene en este medio siglo dos escenarios: media América y Filipinas. En el primer caso se produce escalonadamente la penetración en el interior del continente americano, realizándose desde las ciudades fundadas en el período anterior. Esta ocupación, sin embargo, se formuló con una cierta selección espacial: primando los territorios poblados sobre aquellos que carecían de población aborigen. Y en la definición de esta conquista urbana es digno de resaltarse que se realiza -como final de un proceso de conquista- muy tierra adentro, alejada de las costas, donde los puertos ejercen su papel de promoción, relación e intercambio. El adentramiento 
continental de la expansión española resulta, así, una de las singularidades de la urbanización española y expresión de la más sincera demostración de sus propósitos de permanecer en las nuevas tierras. El poblamiento portugués, por el contrario, se verifica en las costas. Pueblo marinero, al fin, rehuye de la penetración al interior de las regiones, que sólo realizará en Brasil -y a un siglo de distancia de su descubrimiento- y aprovechando coyunturas favorables.

Lo importante también en estas consideraciones sobre expansionismo ibérico es que varias de estas conquistas y fundaciones urbanas se proceden simultáneamente, por lo que este período resulta difícil de abarcar. En la América española se procede a la ocupación de espacios muy alejados entre sí, con la correspondiente fijación de la hueste en un nuevo núcleo urbano: al norte de México-Tenochtitlan (Culiacán, 1531; Guadalajara, 1532), al·sur, en Guatemala (San Miguel, 1530; Valladolid de Comayagua, 1537) y al sureste en Yucatán (Mérida, 1540; Valladolid, 1541). Desde Panamá se procede la expansión por el sur del continente, con la gesta de la ocupación del mundo de los chibchas (Nuevo Reino de Granada), de los incas (Perú), aymaras (Alto Perú -hoy Bolivia-) y de los mapuches chilenos: así en 1553 se fundan Piura y el Cuzco cristiano; 1534, Cajamarca y Quito; 1535, Lima, Arequipa, Guayaquil; 1537, Popayán y Cali; 1538, Chuquisaca; 1539, Santa Fe de Bogotá; 1541, Santiago de Chile; 1544, La Serena; 1550, Concepción, La Imperial, Villarrica; 1552, Angol y Los Confines. Y al otro lado de la cordillera, dependiente de Chile, Mendoza (1561) y San Juan de Cuyo (1562). También en los Andes, péro de Venezuela (1552, Barquisemeto; 1556, Trujillo; 1558, Mérida). Y junto al Caribe, Caracas (1567). Por último, en otro paisaje, en el Río de la Plata, primera fundación de Buenos Aires (1536) y Asunción (1536), a las que siguen Santiago del Estero (1553) y Tucumán (1565).

A este espectacular nacimiento de nuevos núcleos urbanos habría que añadir, para que el proceso resulte completo, la fundación de pueblos de indios, los reales de minas (Potosí, Taxco, Buriticá) y los puertos (Santa Marta, Cartagena de Indias, Acapulco, Callao).

Desde 1573 la Administración española estima concluido para América el período de conquista espacial, dedicándose desde entonces a la colonización sistemática. Las futuras ocupa- 
ciones territoriales se regularían por las Nuevas Ordenanzas de Descubrimiento y Población (sancionadas en 13 de julio, 1573), con normativas muy precisas -incluso urbanísticas-. Se considera, en definitiva, terminado el tiempo de la Conquista para iniciar el de la consolidación territorial. Las fundaciones siguen siendo importantes -en estos años últimos de este período y hasta 1730- pero no tan numerosas como en los tres primeros cuartos del siglo. Pueden señalarse como significativas las fundaciones en la región del Río de la Plata: Santa Fe y Córdoba (1573) y, sobre todo, la segunda y definitiva fundación de Buenos Aires (1580) y Villarrica del Espíritu Santo, en el Itatim paraguayo (1570).

El Oriente español se nace en 1565 cuando, procedente del virreinato de Nueva España, se descubre el tornaviaje a Acapulco, confirmando la posibilidad y la seguridad de integrar Filipinas a México. De esta forma el archipiélago fue una provincia del virreinato de Nueva España hasta 1821. Las características ambientales, culturales, religiosas y étnicas filipinas resultaron muy diferentes de las prehispánicas americanas, que dificultaron y retrasaron la conquista de algunas islas (Mindanao, por ejemplo) y justificaron la fundación de fuertes y presidios. A pesar de ello se aplicaron en Oriente las mismas orientaciones urbanísticas y el trazado en damero -tan fértil en América- creció igualmente al otro lado del Pacífico. Y, asimismo se aplicaron los mismos criterios de colonización con la población aborigen, que fue concentrada en los pueblos de indios -misionados por las órdenes religiosas- mientras una escasa población blanca se radicaba en unas pocas ciudades: en la isla de Cebú, se funda el primer cabildo español en Asia en la aldea denominada San Miguel o Nombre de Jesús en 1565 -que adquiere el rango de ciudad en 1591-; en la isla de Luzón, se fundan Manila (1571), Nueva Cáceres (1579) y Nueva Segovia de Vigán (1581). Las tres eran ciudades costeras, tal como las antillanas, procediéndose desde ellas a la internación bastantes décadas más tarde.

Portugal, por su lado, se expande por entre los trópicos y las costas de dos océanos: sobre todo en el Índico asiático donde los portugueses ocupan numerosos enclaves -ya existentesa los que lusitanizan y, a veces, fortifican: Diú (1533), Beçaim y Damao (1559) en la costa de la India; fortaleciendo Colombo, 
en Ceilán, Malaca. Pero todos estos enclaves -ciudades costeras las más- fueron conquistados estableciendo en ellos, al modo medieval, fuertes intercambios comerciales antes que tentativas colonizadoras, salvo en la isla de Timor. En Brasil, por el contrario, con una población aborigen escasa y dispersa, que carecía de cultura urbana, pudo ensayarse una colonización, que se procedió sobre la base de la urbanización: ya levantando ciudades o formando aldeas para indígenas. Urbanismo que no adquirió, como el español, un modelo arquitectónico y estilístico específico, sino que trasplantó a tierras brasileñas los moldes retorcidos de la villa medieval. La colonización fue encarada, igualmente, sobre pautas bajomedievales. La corona portuguesa dividió el territorio en quince capitanías, con territorios de extensión idéntica en el sentido de los paralelos: cincuenta leguas cada una, que iban desde el Atlántico hasta la línea calculada en Tordesillas. De norta a sur, Pará, Maranhao, Piauí, Ceará, Itamaracá, Pernambuco, Bahía, Ilhéus, Porto Seguro, Espirito Santo, Sao Tomé, Río de Janeiro, Santo Amaro, Sao Vicente y Santana. En las que se fundan los siguientes núcleos urbanos, costeros todos: Sao Vizente (1532), Porto Seguro (1535), Iguaraçú, Ilhéus y Santa Cruz (1536), Olinda (1537), Pernambuco, Santos (1548), Sao Salvador da Bahía de Todos Santos (1549), Vitória (1551), Espirito Santo (1555), Itanhaém (1561) y Río de Janeiro (1565). Como excepción Sao Paulo, en el interior de Santos, fundada en 1558 como aldea de indios, por los jesuitas Nóbrega y el canario Anchieta.

\subsection{De 1580 a 1680}

En 1580 se produce la Unión Ibérica, que representa la culminación de los esfuerzos políticos, desde los años medios de la Edad Media, hacia la formación de un solo estado hispánico -en el sentido romano de la totalidad espacial de la península-. En América del Sur más que la línea de demarcación separaba a las dos administraciones la selva tropical y un enorme espacio boscoso y semidespoblado al sur, en Paraguay, donde los pueblos de indios guaraníes resultaban los vecinos más próximos -aunque muy alejados- de los portugueses de Sao Paulo. Las actividades ilegales (contrabando, emigración clandestina y 
captura de indios cristianos) comenzaron a ser acometidas por los paulistas: que darían ocasión a litigios y controversias pero que, desde 1580, quedaron como problemas internos, capaces de ser resueltos entre ministerios (el Consejo de Indias y el Consejo de Portugal).

Estas actividades ilegales y el proselitismo evangelizador jesuita en las reducciones guaraníes fueron causas próximas de la penetración portuguesa. Los jesuitas se enfrentaron, en primer lugar, con los vecinos españoles de las villas en el Itatim (Jerez de la Frontera, Espíritu Santo) y en el Guairá (Ciudad Real) para evitar que sus indios fueran repartidos en encomiendas entre ellos. Este celo provocó, a la larga, el abandono de estas villas (desde 1675), quedando las aldeas guaraníes como las verdaderas y únicas guardianes de la frontera: sobre las que se precipitó la codicia y el robo de los paulistas, diezmando poblados y vendiendo a sus habitantes como esclavos en las plantaciones de azúcar del nordeste brasileño: a pesar de las reclamaciones de las autoridades y de las excomuniones de los jesuitas. Estos afanes paulistas logran dilatar el territorio portugués, dejando atrás la línea trazada en Tordesillas separadora de jurisdicciones. Gran avance ilícito, pero que fue denunciado, aunque no detenido.

Los monarcas españoles, como Reyes de Portugal, fomentaron el poblamiento, aplicando algunas de las directrices urbanas que tanto éxito habían alcanzado en Hispanoamérica. De este tiempo proceden las fundaciones de Filipeia de Paraíba (hoy Joao Pessoa, 1585), Sao Cristóvao (1590), Natal (1599), Cananea (1600), Sao Luiz (1612), Cabo Frío (1615), Belém de Pará (1616) y Ubatubá (1645). Pero a la vez que se verifican estos logros, se realizan las penetraciones ilícitas de los bandeirantes paulistas en el vecino territorio del Paraguay español, con las misiones guaraníes en el primer término.

Estos avances territoriales, a costa de España, se compensan negativamente con las pérdidas de numerosos enclaves portugueses en Asia, donde se padece un verdadero descalabro y no sólo durante el período de la Unión Ibérica. Las máximas pérdidas se producen después de 1640 , en que se produce el levantamiento del duque de Braganza y la independencia de Portugal. Se pierden Ormuz (1622) y los enclaves próximos (Mascate, Curiate, Basora), Ceilan (entre 1630 y 1660) y Malaca (1640). Las 
fortalezas de la India se rinden en 1653, Cochim en 1665 y media isla de Timor en 1665. El destino oriental de Portugal queda mitigado casi al mínimo (Timor, Diú, Goa, Macau) lo que permite a Portugal dedicarse a Brasil, donde desarrolla un agresivo expansionismo que llega hasta la fundación de Colonia del Sacramento, precedida por la creación de Paranagué (1653), Sao Francisco (1660), Iguaje (1665) y en el altiplano Sorocaba (1661) y Curitiba (1693). La fundación de Colonia de Sacramento (1679), se había verificado -nada menos- que en la orilla izquierda del Río de la Plata, frente a Buenos Aires. Esta flagrante fundación hižo reaccionar a las autoridades españolas que pretendieron solucionar, como en siglos anteriores, los problemas limítrofes por medio de las reuniones de expertos y diplomáticos. Las juntas que se celebran en 1681, en Badajoz y en Elvas, tuvieron este propósito.

Por su lado la continuación de la expansión española por tierras hispanoamericanas se procede, según los criterios de las Nuevas Ordenanzas de 1573, hacia las áreas poco atendidas, sirviendo el núcleo urbano como promocionador de los desarrollos agrícolas, ganaderos y mineros regionales. En Nueva España se fundan San Luis Potosí (1592), Monterrey (1596), Guadalcazar y Lerma (1613), Córdoba (1618) y El Parral (1631); Portobelo en el istmo panameño (1584) y bastantes otros núcleos urbanos en regiones venezolanas -Nueva Barcelona (1634), Clarines (1667)-, en el virreinato peruano -Castro 1586, Oruro 1590, Castrovirreina 1591, Ibarra 1597, Arica 1601- y Chile (Chillán 1580, Colchagua 1585) así como en el Río de la Plata (Salta 1582, Corrientes 1588, La Rioja 1591, Jujuy 1593) y Paraguay (Ciudad Real del Guairá 1575, Jerez de la Frontera 1593).

\section{De 1681 a 1778}

El último período se ubica entre las juntas celebradas en Badajoz y Elvas (1681) y el Tratado de El Pardo (1778) que pone fin a las diferencias territoriales, surgidas por desacuerdos en la aplicación de la línea de Tordesillas. Resulta por diversos motivos -geopolítica, promoción socioeconómica, etc.un período particularmente fértil en fundaciones urbanas. En 
efecto, durante estos cien años se produce un elevado número de fundaciones en los ámbitos de España y de Portugal. En el primer caso el número de fundaciones fue de tal suerte que ha sido comparado el fenómeno con el verificado durante el creativo siglo xVI. La administración española atendió con especial cuidado las áreas periféricas del Imperio, formando en ellas nuevas poblaciones, con el fin múltiple de crear riqueza, ocupar zonas despobladas y frenar la posible ocupación ilegal por parte de otras poblaciones. El ejemplo de Colonia del Sacramento fue muy tenido en cuenta, para evitar situaciones idénticas en alguna de las muchas fronteras que España tenía en América. Son en éstas donde se lleva a cabo la fundación sistemática de pueblos, como un elemento primordial de soberanía. Estas fundaciones se verifican en áreas limítrofes con espacios pertenecientes a otras potencias y empleando la triple tipología ya utilizada (villa, pueblo de indios, presidio) con Inglaterra (en Florida, y norte de México), con Francia (isla Española) y con Portugal (en la ancha frontera desde Venezuela a Paraguay). Pero también las fundaciones se verifican en áreas marginales o despobladas, y en las llamadas "fronteras de guerra» con las etnias aborígenes que rechazaban la urbanización: se incluyen, pues, aquí las fundaciones realizadas en el noroeste y norte de México, en América Central y en Chile.

Como zonas despobladas urgidas de desarrollo se encuentran Uruguay, Patagonia y Chile. La fundación de Montevideo en 1728 fue la respuesta más notable a la penetración ilegal portuguesa, aumentada por la creación de Maldonado y otros núcleos. En el Chile central se produjo un hecho infrecuente, al que se le procuró hallar remedio: la ruralización de la población durante el siglo XVII había dejado vacías a las ciudades. Desde 1740 a 1790 se procedió a la creación de casi un centenar de pueblos, que devuelven la categoría municipal a una población que había perdido -fuera cual fuere la causa- la confianza en la ciudad.

Los ímpetus fundacionales siguen -desde 1778 en que se concluyen estos enfoques- por las áreas anteriormente mencionadas hasta, prácticamente, 1821 en que se produce la emancipación de gran parte de la América española. Pero aquel ánimo fundador se continúa en Cuba, Puerto Rico y Filipinas durante todo el siglo XIX. 
En Brasil, por su lado, los avances esclavistas de los bandeirantes portugueses se transforman desde finales del siglo XVII, cuando se descubren importantes yacimientos metalíferos, en emigraciones de mineros. Las minas de oro fueron la causa de la verdadera penetración al interior de la tierra brasileña: esta sí, jurídicamente portuguesa, acorde con el espíritu de Tordesillas. Como resultado se levantan numerosos efímeros poblados que, en ocasiones, consolidado el mineral dan lugar a villas, y a la promoción regional. Los hallazgos de diamantes consolidaron esta corriente emigratoria. Oro y diamantes dieron lugar a las fundaciones de Cuiabá (1718), Río Verde (1720), Itajubá (1723), Río de Contas (1724) y Vila Boa de Goiás (1725), Tejuco (1739), Paracato (1744), Mariana (1745), Vila Bela (1747) y Oeiras (1761): espacios que conforman Minas Gerais.

El problema Colonia del Sacramento, empero, sí fue un motivo de discordia con los vecinos españoles, y de discordia armada, además. Sin resultado práctico la reunión de Elvas y de Badajoz de 1681 se suceden en las siguientes décadas una serie de acciones militares contra Sacramento, que es ocupada sistemáticamente para, a continuación, recuperarla los portugueses como desenlace de guerras internacionales perdidas por España y las paces concluyentes. Así aquel territorio fue conquistado y reconquistado por tropas españolas en 1705, 1724, 1762 y definitivamente en 1776; para ser devuelto a Portugal en 1714 (Tratado de Utrecht) y en 1763 (Tratado de París). Pero el efecto Colonia del Sacramento potenció el poblamiento de los territorios de la «banda oriental» del Río de la Plata. Fundándose en ella Montevideo, como plaza militar, en 1728 y, más tarde, Maldonado y otras aldeas en el interior.

El intento de solucionar el viejo Tratado de Tordesillas se procedió desde 1745, con envío de expediciones científicas que fijaran astronómica y topográficamente una frontera, lo menos conflictiva posible, divisoria de los espacios portugueses de los españoles. En definitiva una nueva línea de demarcación, correctora del meridiano de Tordesillas. Estos intentos se canalizaron en el Tratado de Madrid (1750), que no fue ratificado, por estimarse excesivo el territorio que iba a ser cedido a Portugal. Después de la reconquista armada de Colonia, en 1776, los Tratados de San Ildefonso (1777) y de El Pardo (1778) concluían -con las concesiones respectivas para cada 
potencia- la larga pervivencia de los enunciados de aquella convención diplomática (Tordesillas 1494), que había dividido al mundo en dos mitades, para que por ellas se expandiera el nervio creador y la iniciativa de los pueblos ibéricos. El altísimo número de ciudades, villas, aldeas, fuertes y présidios creados en el mundo hispánico y en el mundo lusitano -de los que aquí se ha apuntado, apenas, una muestra cronológica de los núcleos urbanos más señalados- resulta la gran consecuencia de los Tratados de Tordesillas.

\section{BIBLIOGRAFIA}

El fenómeno de la urbanización latinoamericana se refleja en una bibliografía tan crecida, como de desigual valor. Son escasos, sin embargo, los estudios que analizan el fenómeno con criterio y visión continental. Con ánimo orientador se señalan los trabajos juzgados como más completos y competentes: es decir, siempre aquellos que abarquen la totalidad de Iberoamérica. Aquella abundancia historiográfica no se produce, sin embargo, con el Extremo Oriente Ibérico, donde las escasas obras aprovechables existentes resultan como verdaderos oasis en un tremendo desierto.

Mi estudio, publicado en 1976, con cerca de 2.000 referencias -y pormenorizado por países y áreas- resulta hasta el presente uno de los escasos que atienden a toda América Ibérica.

SOLANO, Francisco de

«El proceso urbano iberoamericano, desde sus orígenes has-

"ta los principios del siglo XIX».

En Estudios de la Ciudad Iberoamericana. Ed. Francisco de SOLANO.

Marid, CSIC, págs. 727-880, 1976, 2. a edición, Madrid 1983.

La mejor aproximación al Oriente portugués y español se encuentra en las Actas del I Simposio Internacional del Extremo Oriente Ibérico (Madrid 1988), donde se ofrecieron numerosos estudios bibliográficos y sobre fuentes documentales. Se hallan recogidos en

El Extremo Oriente Ibérico. Investigaciones históricas: Metodología y Estado de la cuestión. 
Madrid, Agencia Española de Cooperación Internacional, 1989.

El V Centenario del Tratado de Tordesillas obtuvo su merecida atención, realizándose importantes reuniones científicas, entre las que destaca:

El Tratado de Tordesillas y su época. Congreso Internacional. Valladolid, Junta de Castilla y León, 1995.

\section{Mundo Hispánico}

ALOMAR, Gabriel (Ed.)

De Teotihuacan a Brasilia. Estudios de Historia Urbana Iberoamericana y Filipinas.

Madrid. Instituto de Estudios de Administración Local, 1987.

GASPARINI, Graziano

América, barroco y arquitectura.

Caracas, 1972.

HARDOY, Jorge Enrique

Cartografía urbana colonial de América Latina y el Caribe.

Buenos Aires, SIAP, 1991.

HARDOY, Jorge Enrique y Richard P. SCHAEDEL (Eds.)

Las ciudades de América Latina y sus áreas de influencia a través de la Historia.

Buenos Aires, SIAP, 1975.

MERINO, Luis

Arquitectura y urbanismo en Filipinas, siglos XVI-XIX.

Manila, Ateneo Literario, 1987 y 1989.

MOLINA, Antonio M.

The Philippines through the Centuries.

Manila, 1960.

SCHAEDEL, Richard P., Jorge Enrique HARDOY y N. Scott KINZER (Eds.)

Urbanization in the Americas from its Beginnigs to the Present.

La Haya, 1978.

SOLANO, Francisco de (Coord.)

Estudios sobre la Ciudad Iberoamericana. 
Madrid, 2. ${ }^{a}$ ed. Consejo Superior de Investigaciones Científicas, 1983.

SOLANO, Francisco de

"La ciudad iberoamericana durante el siglo xvIII".

En Estudios de Historia Urbana Iberoamericana y Filipinas, direc.

G. Alomar.

Madrid, 1987, págs. 257-338.

SOLANO, Francisco de

Ciudades hispanoamericanas y pueblos de indios.

Madrid, CSIC, 1990.

SOLANO, Francisco de y M. ${ }^{\mathrm{a}}$ Luisa CERRILLOS (Dirección)

Historia Urbana de Iberoamérica.

Tomo 1.- La ciudad iberoamericana hasta 1573.

Tomo 2.- La ciudad barroca, 1573/1750.

Tomo 3.- La ciudad ilustrada. 1750/1850.

Madrid, Consejo Superior de Arquitectos de España, 1987, 1990, 1992.

VARIOS AUTORES

La ciudad Hispanoamericana. El sueño de un orden.

Madrid, Centro de Estudios Históricos del Ministerio de Obras Públicas, 1989.

La Ciudad Iberoamericana. Actas del Seminario (Madrid 1986).

Madrid, Centro de Estudios Históricos del Ministerio de Obras Públicas, 1987.

Estudios sobre Urbanismo Iberoamericano, Siglos XVI-XVIII.

Sevilla, Junta de Andalucía, 1990.

Obras hidráulicas en América Colonial y Filipinas.

Madrid, Centro de Estudios Históricos del Ministerio de Obras Públicas, 1993.

El Tratado de Tordesillas y su proyección. I Coloquio lusoespañol de Historia de Ultramar. Valladolid, Universidad de Valladolid, 1973 y 1974. 
2. Mundo portugués

AXELSON, E.

Portuguese in South East Africa, 1600-1700.

Witwatersrans, 1960.

AZEVEDO, Aroldo

Vilas e cidades do Brasil colonial.

Sao Paulo.

BOXER, Charles, R.

Fidalgos in the Far East, 1550-1770.

Londres, 1968.

BOXER, Charles R.

The Portuguese Seaborne Empire, 1415-1825.

Londres, 1969.

DELSON, Roberta Max

New towns for colonial Brazil.

Siracusa, 1979.

DIFFIE, Bailey W. y G. WINNIUS

Foundations of the Portuguese Empire (1415-1580).

University of Minnesota Press, 1977.

GALVAO, Henrique y Carlos SELVAGEM

O Imperio ultramarino portugués.

Lisboa, 1950, 1952.

MAGALHAES-GODINHO, Vitorino

L'economie de l'Empire Portugais au XV et XVI siècles.

París, 1969.

MARQUES, Antonio H. de Oliveira

Historia de Portugal.

Lisboa, Verbo, 1972.

MARQUES, Alfredo Pinheiro

Guia de História dos Descobrimentos e Expansao portuguesa.

Lisboa, Biblioteca Nacional, 1987.

MAURO, Frédéric

Le Portugal, le Brésil et l'Atlantique au XvII siècle.

Paris, 1987. 
NORONHA, Antonio Henrique Osorio de Fortificaçoes construidas pelos portugueses no Brasil. Sao Paulo, 1982.

REIS FILHO, Nestor Goulart Evoluçao urbana do Brasil.

Sao Paulo, 1968.

REIS FILHO, Nestor Houlart e Paulo J. V. BRUNA

Catálogo de Iconografía das Vilas e Cidades do Brasil colonial (1533-1720).

Sâo Paulo. Universidade Estadual, 1965.

SALDANHA, Antonio Vasconcelos de As capitanias. $O$ regime senhorial na expansao ultramarina portuguesa.

Funchal, 1992.

SANTOS, Paulo F.

Formaçao de cidades no Brasil colonial.

Coimbra, 1968.

SERRAO, Joaquim Veríssimo

Historia de Portugal.

Lisboa, 1979-1986.

SILVEIRA, Luis

Ensaio de Iconografía das Cidades Portuguêsas do Ultramar.

Lisboa, 1962.

ZENHA, Edmundo

O municipio no Brasil (1552-1700).

Sâo Paulo, 1948.

This article analyses the Spanish and Portuguese expansion from the meridian established in Tordesillas. Since early 16th Century, spatial ocupation reaches disproportionate geographical limits, notwithstanding which the territories are colonized and integrated. This was obtained (also in Asia and Africa) by means of the establishment of urban centers (cities, villas, Indian towns, aldeias) along different phases. It is highlighted the great number of foundations in the Spanish world visà-vis the much less numerous -but significant- foundations in Portuguese America.

R. I., 1996, n. 208 